\title{
Membranes with Favorable Chemical Materials for Pervaporation Process: A Review
}

\author{
Soheila Manshad ${ }^{1 *}$, Mohd Ghazali Mohd Nawawi ${ }^{1}$, Mohammad Reza Sazegar ${ }^{2}$, Hashim Bin Hassan ${ }^{1}$ and Abdulhakim M Alamaria ${ }^{1}$ \\ ${ }^{1}$ Department of Polymer Engineering, Universiti Teknologi Malaysia, 81310 Johor Bahru, Malaysia \\ ${ }^{2}$ Department of Chemistry, Tehran North Branch, Islamic Azad University, Tehran, Iran
}

*Corresponding author: Soheila Manshad, Faculty of Chemical Engineering, Department of Polymer Engineering, Universiti Teknologi Malaysia, 81310 Johor Bahru, Malaysia, Tel: 0060137576114; E-mail: smanshad12@yahoo.com

Received date: June 11, 2016; Accepted date: November 05, 2016; Published date: November 12, 2016

Copyright: ( 2016 Manshad S, et al. This is an open-access article distributed under the terms of the Creative Commons Attribution License, which permits unrestricted use, distribution, and reproduction in any medium, provided the original author and source are credited.

\begin{abstract}
Among many purification processes, pervaporation is one of the promising technologies which is an indispensable component for chemical separations with low energy consumption, minimum contamination and ability to break up azeotropic mixtures. The key success of pervaporation process is dependent on the membrane features (chemical components and morphology). Application of membranes surveyed in three categories included organic solvent dehydration, removal of organics from solvent and separation of organic solvents. This article review discusses different types of pervaporation membranes from the perspective of membrane fabrication and materials in biofuel products.
\end{abstract}

Keywords: Pervaporation; Liquid mixture; separation technology; Diffusion

\section{Introduction}

Pervaporation (PV) process is a process for liquid mixture separation in a liquid phase. This process is able to separate different components from mixtures such as water/organic, organic/water and organic/organic mixtures. Pervaporation process works by placing a liquid mixture to be separated (feed) in contact with one side of a membrane. Across the membrane, the chemical potential gradient works as the driving force for the mass transport of the materials. Also, using vacuum pump or an inert purge (normally air or steam) on the permeate side can help to maintain of a suitable permeate vapor pressure. Usually the kept pressure is lower than the partial pressure of the feed liquid. Finally, the permeated product (permeate) can be removed from the other side with low pressure vapor (Figure 1). In terms of the application or nature of the experiment, the permeate vapor may be collected after condensation or released if desired.

Basically, hydrophilic and hydrophobic membranes apply to separate the aqueous solutions and organic solvents from water mixtures, respectively [1]. PV separation technology has superiority to other separation technologies due to the separation mechanism which is based on the difference in sorption and diffusion properties of the feed substances as well as perm-selectivity of the membrane. This mechanism is not dependent on the relative volatility of components $[2,3]$.

Pervaporation survives the challenge of phase change by two aspects. First, pervaporation uses even with the minor components (usually less than $10 \mathrm{wt} . \%$ ) of the liquid solutions, and second, pervaporation applies the most selective membranes. An efficient membrane need to the suitable membrane materials which can prominent efficiency of performance in the PV performance. Since the minor feed components consume the latent heat, therefore PV techniques reduce energy during the process.

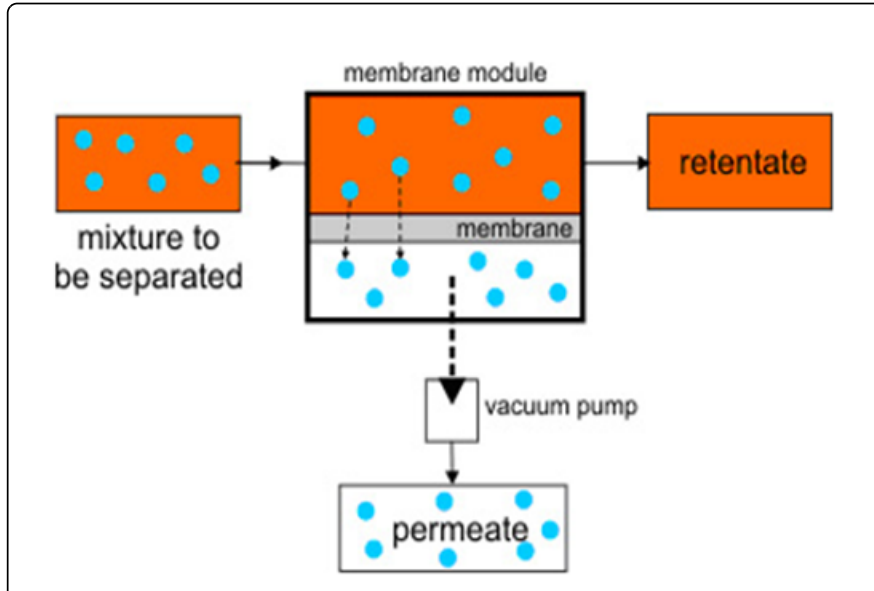

Figure 1: Schematic Diagram of pervaporation process.

The second feature generally allows pervaporation the most efficient liquid-separating technology. Take the separation of isopropanol/water mixtures for example, if water content in the feed stream is $10 \mathrm{wt}$ \%, the maximum single plate separation factor (isopropanol to water) in the fractional distillation is about 2. However, a pervaporation membrane can normally offer a one-through separation factor (water over isopropanol) of 2000-10,000 [4-6]. Furthermore, combination of these two features ranks pervaporation the most cost-effective liquid separation technology [7]. In addition, pervaporation also demonstrates incomparable advantages in separating heat sensitive, close-boiling, and azeotropic mixtures [8-10] due to its mild operating conditions, no emission to the environment, and no involvement of additional species into the feed stream. Most of the membrane materials used in PV techniques are usable in laboratory scale, but not in industrial applications. Thus, there is a need to survey more 
membrane materials possibilities which is important in order to overcome drawbacks in current membranes.

\section{Application of Pervaporation}

Pervaporation technique as a separation process for liquid mixtures is considered to be an economic, safe and environmental friendly technology in comparison to the other conventional energy intensive technologies such as extraction or azeotropic distillation. Since PV is also well-suited for the treatment of volatile organic compounds, hence termed often as a 'clean technology'. PV method categorize into the three different types involves dehydration of aqueous-organic solution [11], removal of volatile organic compounds from aqueous mixture [12] and separation of organic-organic solvent mixtures [13]. Currently, the fractional and azeotropic distillations have been investigated and were used to separate and concentrate alcohol/water mixture. Nowadays, these two processes are still facing suffer from high operating costs and low product yield due to their need to entertainers, while pervaporation technique shows good advantages such as low cost, easy operation and no need to performer [14]. Potential of the industrial utility of this approach attracts for researchers to study the separation of azeotropic solution, pharmaceutical waste, isomeric and heat-sensitive liquid mixtures [15]. The separation performance of a membrane is characterized by two parameters includes flux and selectivity. Flux is the permeation rate of the feed components through unit area of membrane per unit time and measure in terms on $\mathrm{kg} \mathrm{m}^{-2} \mathrm{~h}^{-1}$ or $\mathrm{g} \mathrm{cm}^{-2} \mathrm{~s}^{-1}[16,17]$.

\section{Organic solvent dehydration}

To dehydrate water from the organic liquids or vapor mixtures, hydrophilic polymers as glassy polymers are suitable choices. Their glassy properties provide a good condition to make water-selective membranes which use for solvent dehydrating. Polyacetylene derivatives as samples of glassy polymers, are favourably permeable for organic compounds as compare to water $[2,18,19]$. The hydrophilicity property is due to the presence of the polar groups in the polymer chain that are able to interact with water molecules. Dehydration of organic solvents (e.g., alcohols, ethers, acids and ketones) is the most important applications of pervaporation membranes [4,20-23]. The importance of this process is related to the removal of water from an alcoholic compounds which are used as biofuels that extracted from a fermentation process.

\section{Removal of organics from solutions}

Separation of organic compounds from water is an important process for biofuels recovery which are produced during the fermentation process. For instance, the recovery of biofuels using PV process carry out from a solution of acetone/butanol/ethanol solution which produced by a fermenter. This process requires to a hydrophobic membrane material. Proper of the membrane materials can overcome to environmental and economic challenges. Mostly, rubbery polymer membranes are appropriate for the selective removal of organic compounds from water. However, researchers have found different kinds of membrane materials to separate various organic solvents from their aqueous solutions towards of energy efficient and economic. While among various types of membrane materials, polydimethylsiloxane (PDMS) has better results in terms of the flux and selectivity. Moreover, rubbery polymer membranes are more favorable for the selective removal of the organic compounds from water.

\section{Separation of organic solvents}

Three kinds of mixtures can be distinguished for the mixture of two organic liquids or vapors polar/apolar, polar/polar and apolar/apolar mixtures. For the removal of the polar component from polar/apolar mixture, polymers with polar groups should be chosen and for the removal of the apolar component completely apolar polymers are favorable. The polar/polar and apolar/apolar mixtures are very difficult to separate, especially when the two components have similar molecular sizes. In principle, all kinds of polymers can be used for the separation of both mixtures (polar/polar). The separation process performance on the base of differences in molecular size and shape of the mixtures. In separation of organic mixtures the temperature and pressure have more influence in the rate of transfer and selectivity of the components. However, the temperature will more effect on the organic tertiary mixtures $(\mathrm{ABE})$ in comparison to the binary mixtures [24].

Recently, the ceramic and conducting polymers membranes have been studied as the selective barriers in the PV process [25-27]. Ceramic membranes provide a very high performance. They also contribute a high thermal and chemical stability to the separation process. These membranes can be used for variety applications in order to the separation organic compounds in the acidic or alkaline conditions [28].

\section{Morphology Classification of Membrane}

Membranes used in the process of pervaporation possess porous or non-porous structures. Membranes with or without pores in their structure are called porous and non-porous membranes, respectively. The schematic of various types of the membranes are shown in Figure 2. Difference of their pores size, shapes and distribution are the factors to determine pervaporation efficiency and selectivity of the membranes. In porous membranes, the permeation often carry out by size selection or exclusion. In permeating through the pores by diffusing process, such as separating water from organic solution using $\mathrm{PV}$, a significant amount of water permeates across the membrane. Hence, a higher flux and lower selectivity are observed in the porous membranes. The non-porous membranes function by first partitioning the molecule and then under a concentration gradient allowing it to diffuse through the solid material. So, in the non-porous membrane the partition coefficient and diffusivity effect on the separation of components, therefore, this type of membrane is used for $\mathrm{PV}$ processes whit high selectivity.

Composite membranes, as shown in Figure 2, commonly contain a thin dense surface coating layer above the microporous support layer and the top layer regulate the selectivity of the membrane. It is notable that the membrane materials are differ from the porous support layer $[29,30]$. Efficiency of mixture separation is effected by the physicochemical properties of polymeric membranes as well as operating conditions. The physicochemical properties include thickness, hydrophobicity, chemical compatibility and mechanical strength, and operation conditions include temperature and concentration gradient of the feed across the membrane. Pervaporation membranes fall into two categories, the homogeneous membranes, (Figures 2A, 2B and 2D), and the composite membrane, (Figure 2C). In the last two decades, separation performance for different binary mixtures has been studied, especially the effect of homogeneous membrane thickness [31]. Diffusion process in homogeneous membrane dominates the flux; a higher permeation 
resistance is provided by thicker membrane which decreases the flux but the selectivity is nearly unaffected [4,32]. The composite membrane has a higher permeation flux than homogeneous membranes. This is due to the presence of a thinner homogeneous membrane which is supported on a porous substrate. This makes the composite membrane suitable for the industrial applications. Some studies relate the separation performance in the presence of micropores in the matrix membrane [33] or in the composite membrane's dry layer which is near the permeate side [34].

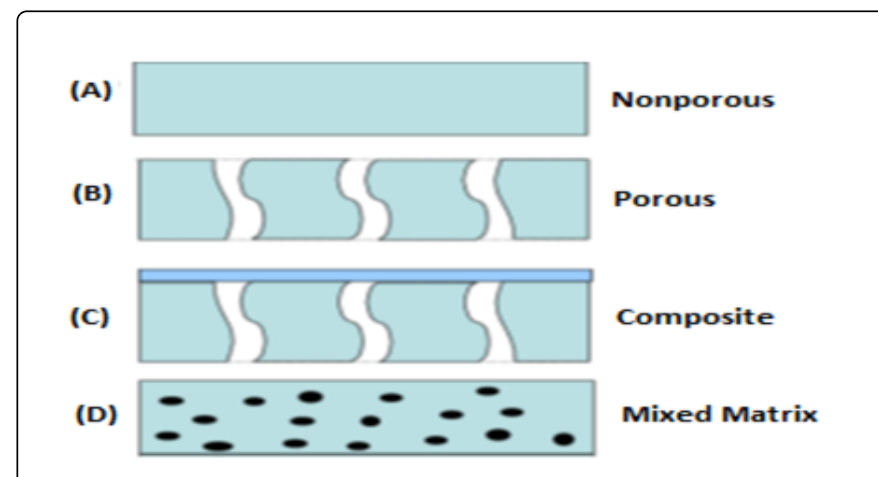

Figure 2: Schematic diagram of membrane morphology.

However, the existence of micropores or dry permeate layers in the membrane is somewhat unclear. If this performance remains unchanged with the membrane thickness, the factors that remain unaffected must be studied. Pervaporation separation, especially with thin membranes, might be effected by the feed-solution adsorption. Thereafter, the following absorption may affect the membrane performance, which would also effect on diffusion and evaporation in the process [29]. In such cases, surface properties, such as hydrophobicity and roughness, can play a crucial role of governing the adsorption and consequent permeating components' absorption. Often, the thinner polymer membranes lack in mechanical stability, which is more apparent when vacuum pressure is applied to the permeate side $[4,31,32,35]$. In recent studies, this problem are addressed by using composite membranes, which support a thin selective layer by a mechanically stable layer $[2,35,36]$. The porous polymers can be used as support layers for the composite membranes, these substrates offer negligible resistances to mass transport $[37,38]$. Otherwise, the substrate resistance may lead to lower membrane productivity and selectivity [39].

Porous polymers such as polysulfone (PSf) are used widely in the ultra-filtration and nano-filtration [40,41], or polyvinyl alcohol (PVA), often used in the PV separation of water/alcohol mixtures. PVA is a hydrophilic polymer with a good chemical stability and low cost of manufacturing $[42,43]$. Since PVA show a tendency to swell in aqueous solution, therefore before use, it must be crosslinked. At the high temperature or intense operation conditions, if the active skin layer and the support layer underneath swell in an un-coordinated manner, the interface experience a big stress [44,45]. It can pass a "critical point" and the composite structure render disintegrated which make the membrane useless. The 'critical point' depends on the two neighboring materials' interactions. For this reason, its structural integrity must also be analyzed other than the factors of selectivity and productivity of the composite membrane. Tailoring the substrate structure achieve a high performance composite membrane.
Composite membranes, however, are not fault-free and have their own limitations. Analysis of the mass transfer resistance showed that the surface resistance of the crosslinked membrane was high for the thin membranes. Statistical analysis showed that the flux was significantly affected by the thickness of the PVA layer [37]. The selectivity was shown to be affected by the surface properties after the membrane crosslinking, especially when the membrane was thin. In the membrane morphology types, a recent development introduced a new composition membrane material which is called Mixed Matrix Membrane (MMM) [46]. MMM, as shown in Figure 2D, contains inter-penetrating polymer matrix and solid fillers, such as graphite, zeolite, silica, carbon molecular sieves, carbon fullerene, cyclodextrin, and metal oxide [46]. The selectivity of the MMMs is around 2000 which is more than twice of neat polymeric membrane. This makes MMMs extremely suitable for breaking the azeotropes solution of water/iso-propanol [47].

\section{Effect of Fillers on MMMs}

According to the studies regarding the effect of the inorganic fillers on MMMs, some researcher reported a tradeoff between flux and separation factor, while the others reported an improvement in both flux and separation factor. Generally, the interfacial voids lead to lower selectivity but higher permeability for water. The enhancements may be attributed to the properties of fillers, their interfacial voids or the polymer chains' rigidification by the fillers. Likewise, increase in flux can be attributed to the high hydrophilicity, high porosity and large pore size of the fillers. The sieving effect of the fillers can be caused an increase in the separation factor for water. The polymer chainrigidification by the fillers might to be a reason for an increase separation factor as the phenomenon reduces permeability. The opposite relationship among the separation factor and flux have resolved by using the inorganic fillers with right pore sizes and good polymer compatibility for a positive enhancement to separation performance [48]. A Mixed-matrix membrane might be useful for water pervaporation, as compared to the inorganic membranes.

Membranes are either hydrophilic or hydrophobic. Although most membranes are hydrophilic or water perm-selective owing to smaller molecular size of water, few membranes are hydrophobic or ethanol perm-selective. Membranes are categorized to inorganic, polymeric and composite membranes, based on the type of materials used for membrane production. The hydrophilic membranes are used for the industrial application through PV process in order to organic solvent dehydration [49,50]. Due to hydrophilic characteristics of these membranes, extraction of water with the flux and selectivity carry out depends on the active layer in the structure and its mode of crosslinks.

\section{Hydrophilic Membranes}

Based on the materials of the membranes and morphology structure of the composite, the hydrophilic membranes classify to inorganic, polymeric and hybrid composite membranes. Hydrophilic membranes are mostly used by two main membrane structures including mixed matrix and composite membranes. Many researchers have focused on the efficiency of mixed matrix and composite membranes, as well as the type of materials which improve transfer rate and selectivity parameters. The polymeric membranes are extensively studied because of their low cost and high performance as compared to the inorganic membranes. On the other hand, the inorganic membranes are excellent in the thermal stability and mechanical integrity. The hybrid membranes are a combination of the polymeric and the inorganic 
membranes in order to enhance the performance of the polymeric membranes.

\section{Polymeric membrane}

Pervaporation dehydration membranes divide into two categories on the base of their hydrophilicity groups. The highly hydrophilic membranes are made by polyvinyl alcohol (PVA) or chitosan. These materials are usually cross-linked to enhance their stability and reduce their swelling in pervaporation feed conditions. The commercial PVA membranes (originally made by GFT) possess high selectivity towards water with reasonably high flux [51,52]. PVA based membranes, however, are not stable with the high feed water content particularly in the high temperature operational condition [50]. Higher feed water content induces the significant swelling on the membranes and the selectivity for water decreases drastically. Hence, the membrane must be cross-linked.

In the membrane technology, there are two reasons for the polymer cross-linking, first, to make the polymer insoluble in the feed mixture and second, to reduce the degree of swelling of polymer for achieving a good selectivity. There are different methods by which cross-linking can be performed such as chemical reactions and heat treatments [53].

Commercially available polyimides such as $\mathrm{P}^{\circ} 4^{\circ}$, Matrimid ${ }^{\circ}$ and Torlon have also been studied recently for pervaporation dehydration applications [18,54-56]. However, a long term performance of polyimides membranes has revealed a possibility of the material hydrolysis which has resulted deterioration of the separation performance over time [57]. Although polybenzimidazole (PBI) membrane possess the high thermal and chemical stability have been applied for pervaporation dehydration, its flux is relatively low due to the strong intermolecular interaction through the hydrogen bonding $[58,59]$. In order to modify the performance of PBI membranes for the commercial application, significant enhancement of its flux should be done. Inorganic and nano-materials were using to remove this drawback of the polymeric membranes. The materials which used in the polymeric membranes are more economic materials than the inorganic and nanomaterial membranes. Therefore, the cost of the polymeric membrane is lower than the others. Recently, researchers have decorated the polymeric membrane using oxidizing raw material like graphite to graphene oxide which reduced the cost of these membranes [60-63].

More recently, pervaporation process through the amorphous perfluoro polymers [50] have been developed to dehydrate alcohols at high temperature. The amorphous perfluoro polymers are co-polymers of tetrafluoroethylene and 2,2,4-trifluoro-5-trifluorometoxy-1,3dioxole with the commercial name of HYFLON"AD. The Hyflon membranes possess the excellent chemical resistance to dehydrate the aprotic solvents such as $\mathrm{N}, \mathrm{N}$-dimethylacetamide [64]. The major disadvantage of these membranes is relatively lower thermal stability due to the Tg of Hyflon which is only $130^{\circ} \mathrm{C}$ [65]. The other researches effort to improve the separation performance.

Particularly flux with the approach of the polyelectrolytes [66,67] and thin film composite (TFC) membranes [68]. The stability of the polyelectrolytes with high amount of water is a major concern since the ionic bonding between the positive and negative ion charges of the polyelectrolytes maybe significantly weakened by the hydrogen bonding between water and the polyelectrolyte molecules. In the ultrathin selective layer produced by the interfacial polymerization (IP), the pervaporation flux is more than $1 \mathrm{~kg} / \mathrm{m} 2 \mathrm{~h}$ at $25^{\circ} \mathrm{C}$ for dehydrating alcohols [68].

This results may be is due to the grafting or proper filler which improved the weakness of this types of polymers. The TFC membranes produced from the IP of the polyfunctional amine and acyl chloride may are not be suitable for very high temperature applications. It may find niche applications where it occur a high flux at the moderate temperature. A list of some polymeric membranes is shown in Table 1.

\begin{tabular}{|c|c|c|c|c|c|}
\hline commercial membrane & Feed compositions (wt\%) & Feed Temperature $\left({ }^{\circ} \mathrm{C}\right)$ & Total flux $\left(\mathrm{Kg} / \mathrm{m}^{2} \mathrm{~h}\right)$ & $\beta$ & Ref. \\
\hline P84 & n-Butanol/water (95/5) & 95 & 1.2 & 1000 & [52] \\
\hline Matrimid & IPA/water (85/15) & 80 & 1.8 & 132 & [17] \\
\hline Torlon & IPA/water (85/15) & 60 & 0.765 & 1944 & [49] \\
\hline PBI & Ethylene glycol/water (64/36) & 60 & 0.732 & 303 & [53] \\
\hline Polyimide (Ube) & Ethanol/water (80/20) & 100 & $0.127(3.5 \mathrm{~mol} / \mathrm{m} 2 \mathrm{spa})$ & 500 & [74] \\
\hline Hyflon/Cellulose ester & Ethanol/water (80/20) & 75 & 1.5 (4000 GPU) & 300 & [47] \\
\hline Polyimide & Ethanol/water (90/10) & 25 & 1.75 & 600 & [75] \\
\hline Polyelectrolytes (simplex GKSS) & Acetone/water (80/20) & 70 & 2.15 & 60 & [70] \\
\hline PVA & IPA/water (90/10) & 80 & 1.2 & 750 & [76] \\
\hline polyelectrolytes & Isopropanol/water (90/10) & 50 & 1.18 & 1013 & [69] \\
\hline
\end{tabular}

Table 1: Commercial polymeric Membrane.

The polymeric membranes show some unfavorable properties such as swelling and low performance in the permeation or separation factors, for using in the PV membranes. However, these weaknesses of the polymeric membranes can be overcome by incorporating low quantities of the specific inorganic components and nanomaterials as modifier.

Research studies were reported the highest performance of PV process when the organic compounds and nanomaterials were used. 
Page 5 of 9

These materials have modified some essential properties such as high permeation and low swelling in the polymeric membranes to achieve to better separation factor. Some studied have stated different advantages of the polymeric and inorganic membranes $[7,69,70]$.

\section{Inorganic membranes}

The membranes which are made from materials such as ceramic, carbon, silica, zeolite, various metal oxides (alumina, titania, zirconia) and metals like palladium, silver and their alloys are known as Inorganic membranes. Based on their structures, these membranes can be categorized as porous inorganic membranes and dense (nonporous) inorganic membranes [71-73]. In the first category, the microporous inorganic membranes, including both of the amorphous and crystalline membranes have two different symmetric and asymmetric structures [74].

The separation of a mixture by inorganic membrane is achieved based on the different molecular sizes of the feed mixture. Several types of the inorganic membranes have been explored for dehydration applications, including zeolite membranes [75], carbon [76,77], silica [78] and graphene [79]. NaA zeolites and silica membranes have been commercialized [7], while the other types of the inorganic membranes are still at the research stage. A first industrial plant with $\mathrm{NaA}$ zeolites was built in 2001 for ethanol dehydration by Mitsui Engineering and Ship building Co. The inorganic membranes have some advantages over the polymeric membrane as mentioned in Table 2.

The inorganic membranes possess high flux which are several times of the polymeric membranes. Among the inorganic membranes, the performance of $\mathrm{NaA}$ zeolite is still the best because of its high hydrophilicity and a pore size of $0.41 \AA$ [7]. Using the carbon membranes prepared from the polymeric precursors have also been attempted for the pervaproation dehydration applications with some promising outcome. More recently, another type of carbon membrane, graphene oxide, has been reported for vapor permeation with ultrahigh water permeability but with almost no permeation to the organic vapor [80-82].

\begin{tabular}{|l|l|}
\hline Inorganic Membranes & Polymeric Membranes \\
\hline $\begin{array}{l}\text { Rigid structure of inorganic materials } \\
\text { resist to swelling materials, } \\
\text { expensive }\end{array}$ & Process-ability, flexxibility and low cost. \\
\hline Thermal and chemical stability & $\begin{array}{l}\text { Thermal, chemical, and mechanical } \\
\text { stability }\end{array}$ \\
\hline Molecular sieve effects & High Selectivity \\
\hline
\end{tabular}

Table 2: Comparision of inorganic and polymeric membranes.

This is a highly interesting phenomenon and may have potential applications for the pervaporation dehydration of the organic mixtures. High costs of the inorganic membranes fabrication is a serious problem for these types of membranes. Hence, it is more efficient to use inorganic materials as a modifier not base membrane materials. Table 3 has exhibited the separation performance of the inorganic zeolitic membranes.

\begin{tabular}{|l|l|l|l|l|l|l|}
\hline Membrane Material & Feed \& Concerntration & Operation $\mathbf{T}^{\circ} \mathbf{C}$ & Total flux $\mathbf{( g / m 2 h )}$ & SF & $\begin{array}{l}\text { Membrane } \\
\text { Structure }\end{array}$ & Ref \\
\hline Zeolite NaA/carboseptube support & $90 \mathrm{wt} \% \mathrm{IPA}$ & 70 & 300 & 2000 & Composite & {$[80]$} \\
\hline Zeolite NaA & $70 \mathrm{wt} \%$ EtOH & 60 & 2100 & 2140 & Composite & {$[81]$} \\
\hline Ceramic commercial membrane & $95 \mathrm{wt} \% \mathrm{IPA}$ & 70 & 2100 & 600 & Tubular & {$[82]$} \\
\hline Pervap SMS $\otimes$ Silicamembrane & $90 \mathrm{wt} \% \mathrm{IPA}$ & 70 & 300 & 60 & Tubular & {$[78]$} \\
\hline
\end{tabular}

Table 3: The seperation performance of the zeolitic membranes.

\section{Nanomaterials}

Nanomaterials can be used as the best modifiers in membranes [63]. However they are not economical but if they use as fillers they will be economical. Using some nanomaterials such as graphene oxide (GO) can be reduced the cost of a membrane $[83,84]$. Many researchers are trying to improve GO properties with decorating of the flaks of GO in the PV process [63].

When nanomaterials are used as fillers they have two main advantages, firstly, low quantity of nanomaterials will give the high sufficient effects in the products, secondly, nanomaterial offer higher selectivity and mostly more stability than the inorganic fillers. Nanomaterials can easily enhance the hydrophilic polymeric or easily change the unfavorable properties of the polymeric materials $[63,83,85]$.

Since the polymeric components are cheaper materials as the basemembrane, therefore nanomaterials are better use as modifiers. Although the organic filler improve the hydrophilicity of a membrane, nano filler get similar result with only one third of the amount of the organic filler and better performance the separation factors. Recent membrane fabrication techniques focus on GO which has considerable results on the performance in dehydration of biofuels [84,86].

Functionalizing and improving the nanomaterials can inspire a novel idea which can change the world of pervaporation by using the new materials for the membrane fabrications. Though researchers attempts to prepare the various membranes in order to dehydration process of the organic solutions and organic mixtures, they could not fabricate an economical membrane which can exhibit the equal performances in the separation and permeation simultaneously. Table 4 is shown a list of the membranes with GO.

\section{Comparison of PV with the Fractional Distillation}

Pervaporation (PV) separation is an economical and a simple method for the separation of many organic/organic mixtures such as azeotropic solutions. It is a competitive method compared to other techniques. Unlike the fractional distillation, the separation mechanism in PV is not based on the components' relative volatility. 


\begin{tabular}{|c|c|c|c|c|c|}
\hline Membrane & $\begin{array}{l}\text { Feed concentration Water } \\
\text { Content }(\%)\end{array}$ & Temperature $\left({ }^{\circ} \mathrm{C}\right)$ & $\begin{array}{l}\text { Permeation } \\
\text { (kgm-2h-1) }\end{array}$ & Seperation factor & Ref. \\
\hline GOPASA/mPAN & 10 & 30 & 2.54 & 2241 & [86] \\
\hline GOPASA/mPAN & 10 & 70 & 4.34 & 1791 & [86] \\
\hline$(($ PEI-modified GO)/PAA)1/PVA/GA & 5 & 50 & 156 & 98.1 & [87] \\
\hline$((\mathrm{PEI}$-modified GO)/PAA)1/PVA/GA & 5 & 40 & 196 & 96.9 & [87] \\
\hline PAN/PVA-GO & 50 & 40 & 27 & 12.9 & [88] \\
\hline GO/AAO & 10 & 50 & 3100 & 230 & [89] \\
\hline GO/AAO & 4.7 & 50 & 1300 & 440 & [89] \\
\hline
\end{tabular}

Table 4: List of membrane ingredient GO.

In fact, it is based on the difference in the sorption and diffusion properties of the feed substances as well as the perm-selectivity of the membrane. The main advantage of PV over distillation is that PV is independent of the relative volatility of components and therefore, it is not limited by the vapor-liquid equilibrium.

Also, since the compounds which pass through the nonporous membrane are evaporated $[87,88]$, it makes a more energy efficient method for PV as compared to the conventional distillation. In addition, pervaporation process do not show any negative influences on the micro-organisms int he fermentation broth $[3,88]$.

\section{Future Possibilities of PV Membrane Material}

Pervaporation processes can be applied for future applications in the different fields of petrochemical industry [89,90], petroleum refinery, environment refinery, food and dairy industry, natural gas refinery and pharmaceutical aspects like process design and product control. Process design give better control of process over PV membrane to improve the quantity of the products [91-96].

Moreover, all kinds of membranes operate to make the satisfactory processes strategy for separating the polar or apolar solutions which decrease the equipment size [97-102], increase the safety, and reduce the product costs.

Pervaporation process is a suitable method for extraction of the organic-aqueous solution and organic-organic mixture due to their properties. Some of these mixtures have poor solubility in water such as toluene, benzene, ethylbenzene, and some of the other components have high solubility in water like methanol, ethanol and isopropyl alcohol [103-108]. Although fractional distillation is also a good method to extract organics such as alcohols which are highly miscible with water, the high process costs and high energy consumption are the major problems for this process. PV membrane is a preferable technique to remove these problems from industrials by breaking azeotropic barriers and/or separating water in low concentration of $10 \%$ wt.

\section{Conclusion}

Pervaporation can compete with well-established separation technologies for biofuel or alcohol separations due to distinctive advantages like economy, safety and ecofriendly nature. Overall, even though there might be some restrictions to overcome, the development of suitable membranes keeping in mind the structure property relationships of the membrane materials, membrane formation techniques and membrane modules. The full potential of pervaporation can be used in the area of alcoholic/water mixture separation. Suitable membrane materials remains a challenge for PV process from both economical and industrial application sides due to the most of the available membranes are experimented in the laboratory scale and not at industrial level. In this review paper, the different types of membranes are reviewed, as well as the challenges they face to perform better in terms of the selectivity and flux simultaneously and have long life membranes.

\section{References}

1. Mulder M (1996) Basic principles of membrane technology.

2. Feng X, Huang RY (1997) Liquid separation by membrane pervaporation: a review. Ind Eng Chem Res 36: 1048-1066.

3. Vane LM (2005) A review of pervaporation for product recovery from biomass fermentation processes. J Chem Technol Biotechnol 80: 603-629.

4. Huang RY (1999) Pervaporation membrane separation processes.

5. Huang R, Pal R, Moon G (1999) Characteristics of sodium alginate membranes for the pervaporation dehydration of ethanol-water and isopropanol-water mixtures. J Mem Sci 160: 101-113.

6. Ezeji TC, Qureshi N, Blaschek HP (2004) Butanol fermentation research: upstream and downstream manipulations. Chem Rec 4: 305-314.

7. Bowen TC, Noble RD, Falconer JL (2004) Fundamentals and applications of pervaporation through zeolite membranes. J Mem Sci 245: 1-33.

8. Qureshi N, Meagher M, Huang J, Hutkins RW (2001) Acetone butanol ethanol $(\mathrm{ABE})$ recovery by pervaporation using silicalite- silicone composite membrane from fed-batch reactor of Clostridium acetobutylicum. J Mem Sci 187: 93-102.

9. Yoshida W, Cohen Y (2003) Ceramic-supported polymer membranes for pervaporation of binary organic/organic mixtures. J mem sci 213: 145-157.

10. Villaluenga GJ, Tabe-Mohammadi A (2000) A review on the separation of benzene/cyclohexane mixtures by pervaporation processes. J Mem Sci 169: 159-174.

11. Guo WF, Chung TS, Matsuura T (2004) Pervaporation study on the dehydration of aqueous butanol solutions: a comparison of flux vs. permeance, separation factor vs. selectivity. J mem sci 245: 199-210.

12. Jiang LY, Chung TS, Rajagopalan R (2007) Matrimid ${ }^{\star} / \mathrm{MgO}$ mixed matrix membranes for pervaporation. AIChE J 53: 1745-1757.

13. Liu R, Qiao X, Chung TS (2005) The development of high performance P84 co-polyimide hollow fibers for pervaporation dehydration of isopropanol. Chem Eng Sci 60: 6674-6686. 
14. Qiao X, Chung TS, Rajagopalan R (2006) Zeolite filled P84 co-polyimide membranes for dehydration of isopropanol through pervaporation process. Chem Eng Sci 61: 6816-6825.

15. Shao P, Huang R (2007) Polymeric membrane pervaporation. J Mem Sci 287: 162-179.

16. Wang Y (2008) Investigation of the fundamental differences between polyamide-imide (PAI) and polyetherimide (PEI) membranes for isopropanol dehydration via pervaporation. J Mem Sci 318: 217-226.

17. Wijmans J, Baker R (1995) The solution-diffusion model: a review. J Mem Sci 107: 1-21.

18. Okada T, Matsuura T (1991) A new transport model for pervaporation. J Mem Sci 59: 133-149.

19. Matsuura T (1993) Synthetic membranes and membrane separation processes: CRC Press

20. Tanimura S, Nakao Si, Kimura S (1990) Ethanol-selective membrane for reverse osmosis of ethanol/water mixture. AIChE J 36: 1118-1120.

21. Fleming HL, Slater CS (1992) Definitions and Background, in Membrane handbook. Springer pp: 105-116.

22. Reddy D, Reineke C (1988) Dehydration with perfluorosulfonic acid ionomer membranes. AIChE Symp Ser 261: 84-92.

23. Bengtsson E, Trägårdh G, Hallström B (1993) Concentration polarization during the enrichment of aroma compounds from a water solution by pervaporation. J food eng 19: 399-407.

24. Enneking L, Stephan W, Heintz A (1993) Sorption and diffusivity measurements of cyclohexane+ benzene and cyclohexene+toluene mixtures in polyurethane membranes Model calculations of the pervaporation process. Bbpc 97: 912-922.

25. Neel J, Aptel P, Clement R (1985) Basic aspects of pervaporation. Desalination 53: 297-326.

26. Aptel P, Challard N, Cuny J, Neel J (1976) Application of the pervaporation process to separate azeotropic mixtures. J Mem Sci 1: 271-287.

27. Jiang LY, Chung TS, Rajagopalan R (2008) Dehydration of alcohols by pervaporation through polyimide Matrimid (R) asymmetric hollow fibers with various modifications. Che Eng Sci 63: 204-216.

28. Khosravi T, Mosleh S, Bakhtiari O, Mohammadi T (2012) Mixed matrix membranes of Matrimid 5218 loaded with zeolite 4A for pervaporation separation of water-isopropanol mixtures. Chem Eng Res Des 90: 2353-2363.

29. Zhu Y, Minet R, Tsotsis T (1996) A continuous pervaporation membrane reactor for the study of esterification reactions using a composite polymeric/ceramic membrane. Chem Eng Sci 51: 4103-4113.

30. Sander U, Soukup P (1988) Design and operation of a pervaporation plant for ethanol dehydration. J mem sci 36: 463-475.

31. Shanley A, Ondrey G, Moore S (1994) Pervaporation finds its niche. Chem eng 101: 34-37.

32. Bruschke H (1995) Industrial application of membrane separation processes. Pure \& appl chem 67: 993-1002.

33. Huang Z, Shi Y, Wen R, Matssura T (2006) Multilayer poly (vinyl alcohol)-zeolite $4 \mathrm{~A}$ composite membranes for ethanol dehydration by means of pervaporation. Sep pur technol 51: 126-136.

34. Guan HM, Chung TS, Huang Z, Kulprathipanja S (2006) Poly (vinyl alcohol) multilayer mixed matrix membranes for the dehydration of ethanol-water mixture. J mem sci 268: 113-122.

35. Okumuş E, Gürkan T, Yılmaz L (2003) Effect of fabrication and process parameters on the morphology and performance of a PAN-based zeolitefilled pervaporation membrane. J mem sci 223: 23-38.

36. Kondo M, Kita H (2010) Permeation mechanism through zeolite NaA and T-type membranes for practical dehydration of organic solvents. J Mem Sci 361: 223-231.

37. Amnuaypanich S, Patthana J, Phinyocheep P (2009) Mixed matrix membranes prepared from natural rubber/poly (vinyl alcohol) semiinterpenetrating polymer network (NR/PVA semi-IPN) incorporating with zeolite $4 \mathrm{~A}$ for the pervaporation dehydration of water-ethanol mixtures. Chem Eng Sci 64: 4908-4918.
38. Rosa ADL, Heux L, Cavaillé JY, Mazeau K (2002) Molecular modeling of the mobility of poly (allyl alcohol), PAA, and poly (vinyl alcohol), PVA. Polymer 43: 5665-5677.

39. Amnuaypanich S, Naowanon T, Wongthep W, phinoyocheep P (2012) Highly water-selective mixed matrix membranes from natural rubberblend-poly (acrylic acid)(NR-blend-PAA) incorporated with zeolite 4A for the dehydration of water-ethanol mixtures through pervaporation. J App Pol Sci 124: E319-E329.

40. Tsai HA, Yue-Ling Y, Kueir-Rarn L, Shu-Hsien H, Maw-Cherng S, et al. (2011) Characterization and pervaporation dehydration of heattreatment PAN hollow fiber membranes. J Mem Sci 368: 254-263.

41. Xia S, Dong X, Zhu Y, Jin W (2011) Dehydration of ethyl acetate-water mixtures using PVA/ceramic composite pervaporation membrane. Sep Pur Technol 77: 53-59.

42. Jeon EJ, Kim AS, Lee YT (2012) Pervaporation of butanol/water mixtures using siloxane polymer/ceramic composite membranes. Desalination and Water Treatment 48: 17-26.

43. Liu G, Hou D, Wei W, Jin W (2011) Pervaporation separation of butanolwater mixtures using polydimethylsiloxane/ceramic composite membrane. Chin J Chem Eng 19: 40-44.

44. Dong Z, Liu G, Liu S, Jin W (2014) High performance ceramic hollow fiber supported PDMS composite pervaporation membrane for biobutanol recovery. J Mem Sci 450: 38-47.

45. Li SY, Srivastava R, Parnas RS (2010) Separation of 1-butanol by pervaporation using a novel tri-layer PDMS composite membrane. J Mem Sci 363: 287-294.

46. Zhou H (2011) Separation of acetone, butanol and ethanol (ABE) from dilute aqueous solutions by silicalite-1/PDMS hybrid pervaporation membranes. Sep Pur Technol 79: 375-384.

47. Kondo M (1997) Tubular-type pervaporation module with zeolite NaA membrane. J Mem Sci 133: 133-141.

48. Zhou M, Persin M (1995) Electrochemically synthesised polypyrrole membranes for the separation of organic mixtures by pervaporation.

49. Zhou M, Persin M, Sarrazin J (1996) Methanol removal from organic mixtures by pervaporation using polypyrrole membranes. J mem sci 117 303-309.

50. Kim J, Bruggen BVD (2010) The use of nanoparticles in polymeric and ceramic membrane structures: review of manufacturing procedures and performance improvement for water treatment. Env Pol 158: 2335-2349.

51. Smitha B, Duraiswamy S, Sridhar SS, Ramakrishna MV (2004) Separation of organic-organic mixtures by pervaporation-a review. J Mem Sci 241: 1-21.

52. Sae-Khow O, Mitra S (2010) Pervaporation in chemical analysis. J Chromatogr A 1217: 2736-2746.

53. Marand E, Pechar TW, Tsapatsis M (2006) Mixed matrix membranes. Google Patents.

54. Alamaria AM, Nawawi MGM, Zamrud Z (2015) Sago/PVA blend membranes for the recovery of ethyl acetate from water. Arab J Chem.

55. Huang HJ, Ramaswamy S, Tschirner U, Ramarao B (2008) A review of separation technologies in current and future biorefineries. Sep pur tech 62: 1-21.

56. Huang Y, Ly J, Nguyen D, Baker RW (2010) Ethanol dehydration using hydrophobic and hydrophilic polymer membranes. Indu Eng Chem Res 49: 12067-12073.

57. Wang Y, Goh SH, Chung TS, Na P (2009) Polyamide-imide/ polyetherimide dual-layer hollow fiber membranes for pervaporation dehydration of C1-C4 alcohols. J Mem Sci 326: 222-233.

58. Zhou F, Koros WJ (2006) Study of thermal annealing on Matrimid ${ }^{\circledast}$ fiber performance in pervaporation of acetic acid and water mixtures. Polymer 47: 280-288.

59. Vrentas J, Duda J (1977) Diffusion in polymer-solvent systems I Reexamination of the free-volume theory. J Poly Sci 15: 403-416.

60. Kreiter R, Wolfs DP, Engelen CWR, Vente JF (2008) High-temperature pervaporation performance of ceramic-supported polyimide membranes in the dehydration of alcohols. J of Mem Sci 319: 126-132. 
61. Wang Y, Gruender M, Chung TS (2010) Pervaporation dehydration of ethylene glycol through polybenzimidazole (PBI)-based membranes 1 Membrane fabrication. J Mem Sci 363: 149-159.

62. Wang KY, Chung TS, Rajagopalan R (2007) Dehydration of tetrafluoropropanol (TFP) by pervaporation via novel PBI/BTDATDI/MDI co-polyimide (P84) dual-layer hollow fiber membranes. J mem sci 287: 60-66.

63. Tang J, Sirkar KK (2012) Perfluoropolymer membrane behaves like a zeolite membrane in dehydration of aprotic solvents. J Mem Sci 421 211-216.

64. Jansen JC, Macchione M, Drioli E (2007) On the unusual solvent retention and the effect on the gas transport in perfluorinated Hyflon $\mathrm{AD}^{\circledR}$ membranes. J mem sci 287: 132-137.

65. Zhao Q (2010) Layer-by-layer self-assembly of polyelectrolyte complexes and their multilayer films for pervaporation dehydration of isopropanol. J Mem Sci 346: 335-343.

66. Urtiaga A, Coterillo CC, Aragoza C, Ortiz I (2003) Dehydration of industrial ketonic effluents by pervaporation. Comparative behavior of ceramic and polymeric membranes. Sep Sci Technol 38: 3473-3491.

67. Fujita H (1961) Diffusion in polymer-diluent systems. Springer 3: 1-47.

68. Tanihara N, Tanaka K, Kita H, Nakagawa K (1992) Vapor-permeation separation of water-ethanol mixtures by asymmetric polyimide hollowfiber membrane modules. J Chem Eng Jap 25: 388-396.

69. Huang SH, Hung WS, Liaw DJ, Lai JY (2010) Interfacially polymerized thin-film composite polyamide membranes: effects of annealing processes on pervaporative dehydration of aqueous alcohol solutions. Sep Pur Technol 72: 40-47.

70. Qiao X, Chung TS, Guo WF, Teoh MM (2005) Dehydration of isopropanol and its comparison with dehydration of butanol isomers from thermodynamic and molecular aspects. J Mem Sci 252: 37-49.

71. Mallada R, Menéndez M (2008) Inorganic Membranes: Synthesis, Characterization and Applications: Synthesis, Characterization and Applications.

72. Morigami Y (2001) The first large-scale pervaporation plant using tubular-type module with zeolite NaA membrane. Sep Pur Technol 25: 251-260.

73. Tin PS, Lin HY, Ong RC, Chung TS (2011) Carbon molecular sieve membranes for biofuel separation. Carbon 49: 369-375.

74. Yoshimune M, Mizoguchi K, Haraya K (2013) Alcohol dehydration by pervaporation using a carbon hollow fiber membrane derived from sulfonated poly (phenylene oxide). J Mem Sci 425: 149-155.

75. Gallego-Lizon T, Edwards E, Lobiundo 'G, Santos LFD (2002) Dehydration of water/t-butanol mixtures by pervaporation: comparative study of commercially available polymeric, microporous silica and zeolite membranes. J Mem Sci 197: 309-319.

76. Nair RR, Wu HA, Jayaram PN, Grigorieva IV, Geim AK (2012) Unimpeded permeation of water through helium-leak-tight graphenebased membranes. Science 335: 442-444.

77. Wee SL, Tye CT, Bhatia S (2008) Membrane separation processpervaporation through zeolite membrane. Sep Pur Technol 63: 500-516.

78. Mahmoudi E (2015) Novel nanohybrid polysulfone membrane embedded with silver nanoparticles on graphene oxide nanoplates. Chem Eng J 277: 1-10.

79. Tsou CH, An QF, Lo SC, Lai JY (2015) Effect of microstructure of graphene oxide fabricated through different self-assembly techniques on 1-butanol dehydration. J Mem Sci 477: 93-100.

80. Chen X, Liu G, Fan Y (2015) Fabrication of graphene oxide composite membranes and their application for pervaporation dehydration of butanol. Ch J Chem Eng 2015.

81. Li G, Shi L, Zeng G, Sun Y (2014) Efficient dehydration of the organic solvents through graphene oxide (GO)/ceramic composite membranes. RSC Advances 4: 52012-52015.

82. Wang N, Ji S, Zhang G, Wang L (2012) Self-assembly of graphene oxide and polyelectrolyte complex nanohybrid membranes for nanofiltration and pervaporation. Chem Eng J 213:318-329.
83. Hyder M, Huang R, Chen P (2008) Effect of selective layer thickness on pervaporation of composite poly (vinyl alcohol)-poly (sulfone) membranes. J Mem Sci 318: 387-396.

84. Koops G, Hendrikman NO, Mulder MHV, Smolders CA (1993) Poly (vinyl chloride) polyacrylonitrile composite membranes for the dehydration of acetic acid. J mem sci 81: 57-70.

85. Pinnau I, Koros WJ (1991) Relationship between substructure resistance and gas separation properties of defect-free integrally skinned asymmetric membranes. Indusl eng chemistry res 30: 1837-1840.

86. Xu W, Paul DR, Koros WJ (2003) Carboxylic acid containing polyimides for pervaporation separations of toluene/iso-octane mixtures. J Mem sci 219: 89-102.

87. Matsui S, Paul D (2003) Pervaporation separation of aromatic/aliphatic hydrocarbons by a series of ionically crosslinked poly (n-alkyl acrylate) membranes. J mem sci 213: 67-83.

88. Vankelecom IF, Broeck SVD, Merckx E, Uytterhoeven JB (1996) Silylation to improve incorporation of zeolites in polyimide films. J Phys Chem 100: 3753-3758.

89. Kulkarni SS (2003) Gas separation membrane with organosilicon-treated molecular sieve. Google Patents.

90. Jia MD, Pleinemann KV, Behling RD (1992) Preparation and characterization of thin-film zeolite-PDMS composite membranes. J Mem Sci 73: 119-128.

91. Li Y, Chung TS (2010) Molecular-level mixed matrix membranes comprising Pebax ${ }^{\circ}$ and POSS for hydrogen purification via preferential $\mathrm{CO} 2$ removal. Inter $\mathrm{j}$ hydro ener 35: 10560-10568.

92. Car A, Stropnik C, Peinemann KV (2006) Hybrid membrane materials with different metal-organic frameworks (MOFs) for gas separation. Desalination 200: 424-426.

93. Ordonez MJC, Balkus KJ, Ferraris JP, Musselman HI (2010) Molecular sieving realized with ZIF-8/Matrimid ${ }^{\oplus}$ mixed-matrix membranes. J of Mem Sci 361: 28-37.

94. Adoor SG, Manjeshwar LS, Bhat SD, Aminabhavi TM (2008) Aluminumrich zeolite beta incorporated sodium alginate mixed matrix membranes for pervaporation dehydration and esterification of ethanol and acetic acid. J Mem Sci 318: 233-246.

95. Qiu S, Liguang W, Guozhong S, Zhang L, Huanlin C, et al. (2010) Preparation and pervaporation property of chitosan membrane with functionalized multiwalled carbon nanotubes. Ind Eng Chem 49: 11667-11675.

96. Zhao Q, Qian J, Zhu C, Song Y (2009) A novel method for fabricating polyelectrolyte complex/inorganic nanohybrid membranes with high isopropanol dehydration performance. J Mem Sci 345: 233-241.

97. Liu Q, Noble RD, Falconer JL, Funke HH (1996) Organics/water separation by pervaporation with a zeolite membrane. J Mem Sci 117: 163-174.

98. Binning R, Lee R, Jennings J, Martin E (1961) Separation of liquid mixtures by permeation. Ind Eng Chem 53: 45-50.

99. Villaluenga J (2005) Analysis of the membrane thickness effect on the pervaporation separation of methanol/methyl tertiary butyl ether mixtures. Sep pur technol 47: 80-87.

100. Spitzen J (1988) The influence of membrane thickness on pervaporation performance.

101. Koops GH, Nolten JAM, Mulder MHV, Smolders CA (1994) Selectivity as a function of membrane thickness: gas separation and pervaporation. J appl poly sci 53: 1639-1651.

102. Osada, Y, Nakagawa T (1992) Membrane science and technology. CRC Press.

103. Pusch W, Walch A (1982) Membrane structure and its correlation with membrane permeability. J Mem Sci 10: 325-360.

104. Du R, Zhao J (2004) Properties of poly (N, N-dimethylaminoethyl methacrylate)/polysulfone positively charged composite nanofiltration membrane. J Mem Sci 239: 183-188. 
Citation: Manshad S, Nawawi MGM, Sazegar MR, Hassan HB, Alamaria AM (2016) Membranes with Favorable Chemical Materials for Pervaporation Process: A Review. J Membr Sci Technol 6: 164. doi:10.4172/2155-9589.1000164

Page 9 of 9

105. Du R, Feng X, Chakma A (2006) Poly (N, N-dimethylaminoethyl methacrylate)/polysulfone composite membranes for gas separations. J Mem Sci 279: 76-85.

106. Yeom CK, Lee KH (1996) Pervaporation separation of water-acetic acid mixtures through poly (vinyl alcohol) membranes crosslinked with glutaraldehyde. J Mem Sci 109: 257-265.
107. Uragami T, Kato S, Miyata T (1994) Structure of chemically modified chitosan membranes and their characteristics of permeation and separation of aqueous ethanol solutions. J Mem Sci 88: 243-251.

108. Niemistö J, Kujawski W, Keiski RL (2013) Pervaporation performance of composite poly (dimethyl siloxane) membrane for butanol recovery from model solutions. J Mem Sci 434: 55-64. 